\title{
Search for genomic regions associated with potato starch granules morphology of Solanum tuberosum L.
}

\author{
T.V. Erst ${ }^{1}$, I.V. Rozanova ${ }^{1,2}$, V.K. Khlestkin ${ }^{1,3}$, E.K. Khlestkina ${ }^{1,2}$ \\ ${ }^{1}$ Institute of Cytology and Genetics, SB RAS, Novosibirsk, Russia \\ ${ }^{2}$ N.I. Vavilov All-Russian Research Institute of Plant Genetic Resources (VIR), St. Petersburg, Russia \\ ${ }^{3}$ Russian Research Institute of Farm Animal Genetics and Breeding - Branch of the L.K. Ernst Federal Science Center for Animal Husbandry, St. Petersburg, Russia
}

DOI 10.18699/ICG-PlantGen2019-70

(c) Autors, 2019

*e-mail: erst@bionet.nsc.ru

\begin{abstract}
Potato (Solanum tuberosum L.) is one of the world's main crops for food and industrial applications. Potato starch consists of two types of glucose polymers, essentially linear amylose and highly branched amylopectin. Polymers comprising raw starch granules are packed in a layered structure consisting of alternating crystalline and amorphous layers. Average granule shape and size parameters vary for various varieties. The study of the morphological parameters of granules can provide a deeper understanding of the biochemical mechanisms of their formation and reactivity in (bio)chemical transformations. The morphology of starch granules are supposed to be primarily determined by starch biosynthesis genes, in particular, by genes that encode SBEI and SBEll enzymes (Starch Branching Enzyme). However, the set of genes affecting granule morphology is probably much wider. Different starch applications may require certain shapes and size of starch granules. To reveal genetic control of starch granule morphology, genome-wide association studies (GWAS) have been performed. For the morphological trait called the "circularity" character data analysis with the use of a Generalized Linear Model with Principal Component Analysis (GLM + PCA) revealed a significant association with a SNP located on chromosome 11. A detailed study of the identified genomic region is being conducted in order to design a proper diagnostic DNA-marker for further accelerated selection of plants with the required values of morphological starch granule parameters.
\end{abstract}

Key words: starch granule morphology; genome-wide association studies; potato starch.

\section{Introduction}

Potato (Solanum tuberosum L.) is one of the world's main crops for food and industrial applications. Potato is a food crop with a global production of 388 million tons in 2017 (http://www.fao.org/faostat/en/\#data/QC). The starch granules consist of amylose and amylopectin polymer molecules consisting of glucose residuals' monomers. There are several possible ways of starch industrial application. First, such applications may be based on the polymeric nature of starch: for food industry as a thickener, texturant, extender, low-calorie snacks; for paper industry: beater sizing, surface sizing, coating; for textile utilization: wrap sizing, finishing, printing; for polymer applying: absorbents, adhesives, biodegradable plastics. Second, starch may be applied after hydrolysis of its polymer molecules. Hydrolysis gives glucose, maltose or dextrins required by food industries as sweeteners or stabilizing agents; by fermentation process as a feedstock to produce ethanol, liquors, spirits, beer, etc.; by pharmaceutical application as a feedstock to produce drugs and medicine; by chemical industry as a feedstock to produce organic solvents or acids (Jansson et al., 1997; Geigenberger, Fernie, 2012).

\section{Granule morphology is related with starch properties}

Starch granules' shape and size can affect starch properties. Industries require starch with granules of certain shape and size. It is known that the paper industry requires that granules be uniform in size and spherical in shape. There is the absence of such uniform characteristics in native starch and to avoid further granule modification it is possible to cultivate certain granule shape and size variety (Guo et al., 2010). Viscosity of a starch paste is mainly a function of the size of swollen granules (Grommers, Krogt, 2009). Starch content increases with tuber growth. This increase is caused both by an increase in the number of granules and by an enlargement of granules. The size of potato starch granules in a mature tuber may range from $5 \mu \mathrm{m}$ to about $120 \mu \mathrm{m}$. The largest granules are often present in the large cells of the perimedullary zone. Small granules largely occur in the tissue around the vascular ring. The cells of the cortex contain the largest number of granules per cell; the smallest number of cells are found in pith and medullary rays. (Grommers, Krogt, 2009).

Considering the process of enzymatic hydrolysis of starch, in particular, the process of digestion in humans and other mammals, it is known that the rate of the process is affected by several factors. For example, high-amylose starches are more resistant to hydrolysis (Morita et al., 2007) in comparison to normal starches, where the percentage of amylose varies within $20-30 \%$. Crystallinity is generally considered to restrict hydrolysis (Ring et al., 1988; Planchot et al., 1997; Dhital et al., 2010), supramolecular structures such as amylose lipid complexes (Karkalas et al., 1992; Lauro et al., 1999) and phosphorylation of amylopectin (Sitohy et al., 2001) also affect the hydrolysis process. Starches of different potato varieties are similar in composition and structure. Thus, the size of the granules is the main morphological factor affecting starch degradation. On the one hand, if the processed starches 
are used in the human diet, then morphological factors become more or less unimportant for digestion. On the other hand, raw native starch contained in meals from unprocessed potatoes also presents in human nutrition. In addition, some products and therapies do contain native starches to control the release of glucose (Qi, Tester, 2005; Correia et al., 2008). Such products are designed to release glucose into the blood stream slowly with a decreased initial glucose spike (Qi, Tester, 2005; Correia et al., 2008). Besides size, some features of the surface of the granules affect the enzymatic hydrolysis of starch. Granule shape peculiarities affect the way enzymes attach and accelerate granules hydrolysis (Colonna et al., 1992). Starches consisting of small granules are digested in the human intestine to glucose faster than larger ones (Qi, Tester, 2005). Eating large starch granules can cause lesions in the intestine (Calvert et al., 1989). Therefore, the use of such large granules for food is undesirable.

\section{Genetic mechanisms}

\section{underlying granule morphology}

Starch granule morphology and crystallinity are regulated by starch biosynthesis genes (Yamamori et al., 2000). It is known that amylopectin chains branching, size (Hofvander et al., 2004) and irregular granule shape (Schwall et al., 2000) are affected by the $S B E I$ and $S B E I I$ genes (starch branching enzyme). Tuber starch content and irregular granule shape (Schwall et al., 2000) are likely to be affected by SSI-SSIV (starch synthases). However, it can be assumed that the set of genes affecting the morphology of the granules is wider than just the structural genes of starch biosynthesis.

The search for genomic regions associated with potato starch granule morphology can be provided in several ways: as quantitative trait locus (QTL) analysis (Werij et al., 2012) or genome-wide association studies (GWAS). In our research, we used the second approach.

Starch of 90 potato cultivars and hybrids from the collection of the Genetic Control Center «GenAgro» (IC\&G SB RAS) was extracted using a routine procedure described by Khlestkin, Erst (2017). Starch granule size and shape were measured, and the mean values were calculated. For example, the "circularity" trait (describes granule shape from 1 (ideal circle) to 0 (rectangle)) varies in the selection from 0.79 (cultivar 'Ladozhsky') to 0.87 (perspective line G.3-43-6). Thus, contrast phenotype samples were found. The set of 90 cultivars and lines was genotyped using the Illumina 22K SNP potato array (GGP Potato V3). Genotyping and phenotyping data were analyzed using Microsoft Excel, Tassel 5, and the R package. As a result, SNPs significant for starch granule morphology have been revealed on chromosomes 2, 4, 7, and 11 .

\section{Conclusions}

Our study demonstrated genetic diversity within the panel analyzed for starch granule morphology. Based on GWAS, significant SNPs were found on chromosomes 2, 4, 7, and 11. In the regions associated with starch granule morphology variation, candidate genes can be found in the future. Genetic markers found to be associated with certain traits of starch granules are important for further accelerated breeding of cultivars with the required starch properties.

\section{References}

Calvert R.J., Otsuka M., Satchithanandam S. Consumption of raw potato starch alters intestinal function and colonic cell proliferation in the rat. J. Nutr. 1989;1610-1616.

Colonna P., Leloup V., Buleon A., Limiting factors of starch hydrolysis. Eur. J. Clin. Nutr. 1992;46:S17-S32.

Correia C.E., Bhattacharya K., Lee P J., Shuster J.J. et al. Use ofmodified cornstarch therapy to extend fasting in glycogen storage disease types Ia and Ib. Am J. Clin Nutr. 2008;88:1272-1276.

Dhital S., Shrestha A.K., Gidley M.J., Relationship between granule size and in vitro digestibility of maize and potato starches. Carbohydr. Polym. 2010;82:480-488.

Geigenberger P., Fernie A.R. Starch Synthesis in the Potato Tuber. Food Biochemistry and Food Processing. 2012:613-626.

Grommers H.E., van der Krogt D.A. Potato Starch: Production, Modifications and Uses. In: Miller J., Whistler R. (Eds.). Starch Chemistry Technol. 3rd Edn. Elsevier Inc. 2009;511-539. ISBN: 978-0-12-746275-2.

Guo S., Tang J., Deng Y. et al. BMC Genomics. 2010;11(Suppl 2): S13. DOI 10.1186/1471-2164-11-S2-S13.

Hofvander P., Andersson M., Larsson C.-T., Larsson H. Field performance and starch characteristics of high amylose potatoes obtained by antisense gene targeting of two branching enzymes. Plant Biotechnol. J. 2004;2:311-320. DOI 10.1111/j.1467-7652.2004.00073.x.

Jansson C. et al. Cloning, characterisation and modification of genes encoding starch branching enzymes in barley. In: Frazier P.J. et al. (Eds.). Starch Structure and Functionality. The Royal Society of Chemistry, Cambridge. 1997;196-203.

Karkalas J., Tester R.F., Morrison W.R., Properties of damaged starch granules. I. Comparison of a micromethod for the enzymic determination of damaged starch with the standard AACC and Farrand methods. J. Cereal Sci. 1992;16:237-251.

Khlestkin V.K., Erst T.V. A practical guide to the starch granules' morphology study by microscopy. Vavilovskii Zhurnal Genetiki $i$ Selektsii = Vavilov Journal of Genetics and Breeding. 2017;21(6): 728-734. DOI 10.18699/VJ17.290 (in Russian).

Lauro M., Forssell P.M., Suortti M.T., Hulleman S.H.D., Poutenen K.S., Alpha-amylolysis of large barley starch granules. Cereal Chem. 1999;76:925-930.

Morita T., Ito Y., Brown I.L., Ando R., Kiriyama S. In vitro and in vivo digestibility of native maize starch granules varying in amylose contents. J. AOAC Int. 2007;90:1628-1634.

Planchot V., Colonna P., Buleon A., Gallant D.J. In: Frazier P.J., Donald A.M., Richmond P. (Eds.). Starch: Structure and Functionality, The Royal Society of Chemistry, Cambridge, UK, 1997;141-152.

Qi X., Tester R. T., Effect of native starch granule size on susceptibility to amylase hydrolysis. Starch = Stärke. 2016;68(9-10):807-810. DOI 10.1002/star.201500360.

Ring S.G., Gee J.M., Whittam M., Orford P., Johnson I.T. Resistant starch: Its chemical form in foodstuffs and effect on digestibility in vitro. Food Chem. 1988;28:97-109.

Schwall G.P., Safford R., Westcott R.J., Jeffcoat R., Tayal A., Shi Y.-Ch., Gidley M.J., Jobling S.A. Production of very-high-amylose potatostarch by inhibition of SBE A and B. Nat. Biotechnol. 2000;18: 551-554. DOI 10.1038/75427.

Sitohy M.Z, Ramadan M.F. Degradability of different phosphorylated starches and thermoplastic films prepared from corn starch phosphomonoesters. Starch = Stärke. 2001;53:317-322.

Werij J.S., Furrer H., van Eck H.J., Visser R.G.F., Bachem C.W.B. A limited set of starch related genes explain several interrelated traits in potato. Euphytica. 2012;186:501-516. DOI 10.1007/s10681-0120651-y.

Yamamori M., Fujita S., Hayakawa K., Matsuki J., Yasui T. Genetic elimination of a starch granule protein, SGP-1, of wheat generates an altered starch with apparent high amylose. Theor. Appl. Genet. 2000; 101:21-29. DOI 10.1007/s001220051444.

Acknowledgements. The work supported by a grant from the RFBR (No. 17-29-08006).

Conflict of interest. The authors declare no conflict of interest. 